\title{
Relation of anthropometric and dynamometric variables to serious postoperative complications
}

\author{
A M KLIDJIAN, K J FOSTER, R M KAMMERLING, A COOPER, S J KARRAN
}

\begin{abstract}
Summary and conclusions
Prediction of serious postoperative complications by using standard anthropometric and biochemical nutritional variables was attempted in 225 patients admitted for major abdominal surgery. In 102 of the patients handgrip dynamometry was also measured, and this proved the most sensitive test, predicting complications in 48 of the 55 patients $(87 \%)$ who developed them $(p<0.001)$. Arm muscle circumference and forearm muscle circumference below $85 \%$ of the standard value were also of predictive value $(p<0.02$ and $p<0.01$ respectively); weight for height and serum albumin concentrations were less satisfactory, while weight loss of more than $10 \%$ was not significantly related to complications.
\end{abstract}

Dynamometry is a useful, rapid, and inexpensive screening test for detecting malnutrition that is likely to predispose to serious postoperative morbidity.

\section{Introduction}

Malnutrition is common in surgical practice ${ }^{1}$ and is a major factor in postoperative morbidity. ${ }^{2}$ As early as 1936 Studley $^{3}$ noted that a third of patients who had lost $20 \%$ of their weight died after operations for peptic ulcer, but it has proved difficult to establish clinically useful measures of malnutrition that reliably predict postoperative complications. ${ }^{4}$ Depleted protein is the factor most closely associated with postoperative complications. In a preliminary communication ${ }^{5}$ we reported that estimation of skeletal-muscle protein by measurement of arm muscle circumference predicted serious complications more reliably than measurement of weight, weight loss, or serum albumin concentration.

We now present the results of measurement of arm muscle protein, including functional assessment by dynamometry, in relation to postoperative morbidity in 225 patients undergoing abdominal operations.

\section{Patients and methods}

We studied 225 patients admitted for elective major abdominal operations (table I). Ninety-two patients underwent cholecystectomy, 48 gastroduodenal operations, 54 colorectal operations, and 31 other procedures. Sixty-eight had neoplastic conditions and 11 inflammatory bowel disease.

Preoperative measurements were made of weight in relation to height (expressed as a percentage of ideal body weight, using the midpoint of the range for medium frame in the Metropolitan Life Insurance tables) ${ }^{6}$ ); estimated weight loss in the previous six months (expressed as a percentage of actual weight); muscle bulk, assessed by arm muscle circumference and forearm muscle circumference; muscle

\footnotetext{
Department of Surgery, University of Southampton, Southampton General Hospital, Southampton

A M KLIDJIAN, FRCS, surgical research registrar

$\mathrm{K} J$ FOSTER, DM, MRCP, lecturer in medicine

R M KAMMERLING, BM, senior house officer

A COOPER, BM, house surgeon

S J KARRAN, FRCS, senior lecturer in surgery
}

function, assessed by hand-grip strength using a simple hand-grip dynamometer; and plasma albumin concentration, using a Vickers M300 autoanalyser and the bromcresol green method.

Arm muscle circumference was derived, after measuring the arm circumference and triceps skinfold thickness with Harpenden skinfold callipers, by the formula arm muscle circumference = arm circumference $-(\pi \times$ triceps skinfold thickness $)$ and expressed as a percentage of the standard values. ${ }^{7}$ Forearm muscle circumference was measured similarly at the midpoint of the forearm and expressed as a percentage of normal control values, which had been obtained in a preliminary study. Grip strength was measured on the non-dominant arm with a simple hand-grip dynamometer. Three values were taken and the highest used, expressed as a percentage of control values (see below).

For the purpose of this study, a serious complication was defined as one that delayed the postoperative period in hospital by more than 14 days or resulted in death.

Control values for forearm muscle circumference and grip strength were obtained in 284 healthy patients ( 90 men, 194 women) admitted for minor operations or as day cases. The mean age of these patients was $49 \cdot 1$ years.

Statistical differences between means were compared by using Student's $t$ test, and linear correlations between variables sought using standard methods. The significance of the incidence of postoperative complications was assessed for weight loss greater than $10 \%$; serum albumin concentration less than $35 \mathrm{~g} / 1$; and weight, arm muscle circumference, forearm muscle circumference, and grip strength at successive fifth percentile points below the $100 \%$ standard using the $\chi^{2}$ test with Yates's correction. ${ }^{8}$

TABLE I-Details of patients

\begin{tabular}{lccc}
\hline & All patients & $\begin{array}{c}\text { Patients undergoing } \\
\text { cholecystectomy }\end{array}$ & $\begin{array}{c}\text { Patients undergoing } \\
\text { other major } \\
\text { operations }\end{array}$ \\
\hline No of patients & 225 & 92 & 133 \\
No of men & 104 & 31 & 73 \\
No of women & 121 & 61 & 60 \\
Age range (years) & $16-81$ & $21-81$ & $16-81$ \\
Mean age (years) & 56.6 & 52.6 & $59 \cdot 3$ \\
No (\%) with & $55(24 \%)$ & $3(3 \%)$ & $52(39 \%)$ \\
complications & 5 & & \\
\hline
\end{tabular}

\section{Results}

In the control patients the mean $( \pm \mathrm{SD})$ forearm muscle circumference was $23.5 \pm 1.6 \mathrm{~cm}$ in the men and $19.2 \pm 1.6 \mathrm{~cm}$ in the women; grip strength was $48.8+7.0 \mathrm{~kg}$ in the men and $34.4+4.7 \mathrm{~kg}$ in the women. Forearm muscle circumference correlated significantly with grip strength (men: $\mathrm{n}=90, \mathrm{r}=0.69, \mathrm{p}<0.001$; women: $\mathrm{n}=194$, $\mathrm{r}=0.74, \mathrm{p}<0.001)$ and with arm muscle circumference (men: $\mathrm{r}=0.82$, $p<0.001$; women: $r=0.84, p<0.001)$. The coefficient of variation for repeated estimations by the same observer was $1.6 \%$ for forearm muscle circumference and $5.4 \%$ for grip strength.

Table II compares the incidences of low estimations of body protein and postoperative complications in the patients for each variable; in each case the threshold value shown is the one that gave the highest significance coupled with the greatest accuracy. Weight loss below $10 \%$ was the only variable whose predictive value was not significant. Weight below $90 \%$ that expected for height was significant $(p<0.05)$, as were arm and forearm muscle circumferences $(p<0.02$ and $\mathrm{p}<0.01$ respectively). The most significant predictive variables were grip strength below $85 \%$ of the standard value and albumin concentration below $35 \mathrm{~g} / 1(\mathrm{p}<0.001)$. Overall, of the 55 patients who developed complications, $48(87 \%)$ had a low grip strength. In four patients accurate measurement of grip strength was not possible because of local disease of the hand (rheumatoid arthritis in three, recent orthopaedic surgery in one). 
TABLE II-Proportions of patients with complications for each variable measured. Threshold values are expressed as percentages of normal values

\begin{tabular}{|c|c|c|c|c|c|c|c|c|c|c|c|c|}
\hline & \multicolumn{2}{|c|}{$\begin{array}{l}\text { Weight for } \\
\text { height } \\
(n=225)\end{array}$} & \multicolumn{2}{|c|}{$\begin{array}{l}\text { Weight loss } \\
(\mathrm{n}=225)\end{array}$} & \multicolumn{2}{|c|}{$\begin{array}{c}\text { Arm muscle } \\
\text { circumference } \\
(\mathbf{n}=225)\end{array}$} & \multicolumn{2}{|c|}{$\begin{array}{c}\text { Forearm muscle } \\
\text { circumference } \\
(n=102)\end{array}$} & \multicolumn{2}{|c|}{$\begin{array}{l}\text { Grip strength } \\
\quad(\mathrm{n}=102)\end{array}$} & \multicolumn{2}{|c|}{$\begin{array}{c}\text { Albumin } \\
\text { concentration } \\
(\mathbf{n}=\mathbf{2 2 5})\end{array}$} \\
\hline & $<90 \%$ & $\geqslant 90 \%$ & $\geqslant 10 \%$ & $<10 \%$ & $<85 \%$ & $\geqslant 85 \%$ & $<85 \%$ & $\geqslant 85 \%$ & $<85 \%$ & $\geqslant 85 \%$ & $<35 \mathrm{~g} / 1$ & $\geqslant 35 \mathrm{~g} / 1$ \\
\hline $\begin{array}{l}\text { No of patients } \\
\text { No (\%) with complications } \\
\text { Significance }\end{array}$ & $\begin{array}{c}40 \\
15(38) \\
p<\end{array}$ & $\begin{array}{c}185 \\
40(22) \\
.05\end{array}$ & $99^{33}(27)$ & $S^{46(24)}$ & $\begin{array}{l}41 \\
16(39) \\
\mathrm{p}<\end{array}$ & .02 & $9 \stackrel{18}{p<}$ & $14(17)$ & $\begin{array}{c}44 \\
20(45) \\
p<\end{array}$ & $3^{58}(5)$ & $\begin{array}{c}25 \\
13(52) \\
p<0 .\end{array}$ & $\begin{array}{c}200 \\
42(21) \\
001\end{array}$ \\
\hline
\end{tabular}

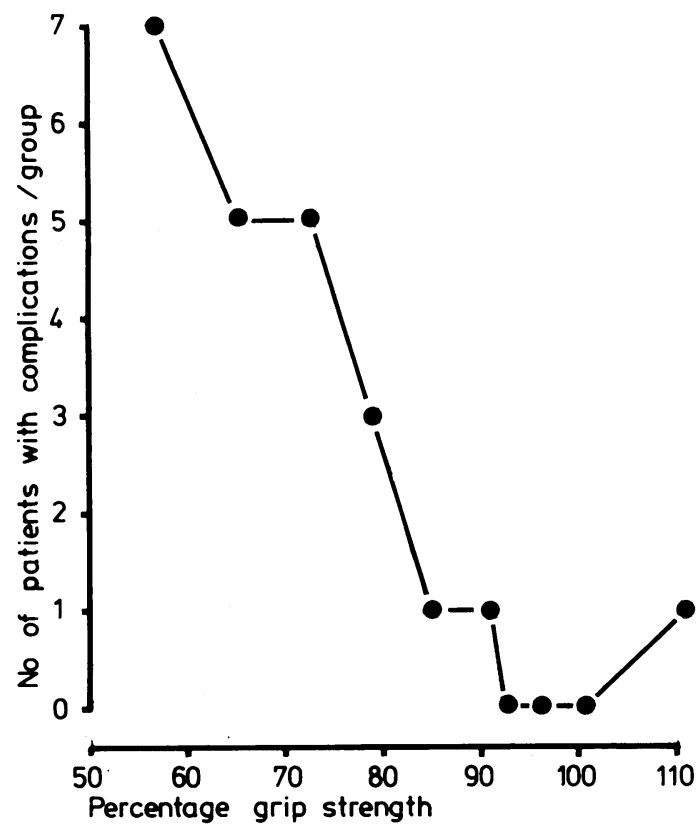

Grip strengths in patients with and without complications. Patients were grouped in tens according to grip strength.

Regression analysis of these results (figure) was made by grouping the patients in batches of 10 according to grip strength. The group with the lowest grip strength had the highest incidence of complications $(70 \%)$. There was an inverse linear relation between grip strength and complications.

As expected, the patients who had undergone cholecystectomy had a low incidence of serious complications ( $3 \%$ ). When the 133 other patients were considered alone preoperative forearm muscle circumference and grip strength again proved to be the best prognostic variables. Out of 63 patients tested, 13 had a low forearm muscle circumference, of whom nine $(69 \%)$ developed complications $(\mathbf{p}<0.01)$; and 34 had a low grip strength, of whom $20(59 \%)$ developed complications $(p<0.001)$.

Half of the patients with an albumin concentration below $35 \mathrm{~g} / 1$ developed complications, but hypoalbuminaemia was found in only $10 \%$ of patients overall.

The seniority of the surgeon, the duration of the operation, and the clinical staging of malignant tumours had no statistical correlation with postoperative morbidity.

\section{Discussion}

Several factors cause complications in surgical patients, but malnutrition appears to be one of the most important. ${ }^{9}$ The possibility that operative morbidity and mortality may be reduced by preoperative detection of serious malnutrition, with subsequent correction by active nutritional support, ${ }^{10}$ offers an important therapeutic approach. Methods of detecting malnourished patients are not yet satisfactory ${ }^{2}$ but to be effective must be rapid, reproducible, and preferably inexpensive.

Measurements that largely reflect obesity such as weight loss and weight for height were less successful than estimates of skeletal protein and plasma albumin concentrations in detecting malnutrition. These findings confirm the importance of protein depletion rather than energy depletion in predisposing to postoperative morbidity. Loss of other intracellular components, such as vitamins and minerals, may also be important. We now define appreciable protein depletion as existing when arm or forearm muscle circumference is below $85 \%$ of the standard, grip strength is below $85 \%$ of normal, or plasma albumin concentration below $35 \mathrm{~g} / \mathrm{l}$.

Hypoalbuminaemia has been claimed accurately to reflect malnutrition, ${ }^{11}$ and a low preoperative albumin concentration showed a high degree of significance in our patients. Compared with grip strength, however, it was relatively insensitive, detecting less than half the patients who later developed complications. Concentrations of other serum proteins such as retinol-binding protein may prove helpful but have yet to be fully evaluated. ${ }^{12}$ Some workers have attempted to provide a prognostic nutritional index by using several tests. ${ }^{13}$ The complexity of the formula and its dependence on laboratory tests limit the usefulness of such an index.

Hand-grip dynamometry proved the most sensitive test in our studies. In addition, it fulfils many of the criteria for a useful test of preoperative malnutrition. Local defects such as paralysis, arthritis, and trauma obviously impair grip strength, but these are rare, occurring in less than $4 \%$ of patients tested. Grip strength was low in $48(87 \%)$ of the 55 patients who developed complications; but of those patients who had gastric, pancreatic, or colonic operations (procedures previously characterised as conferring high risk $\left.^{5}\right), 20$ out of 21 with complications $(95 \%)$ had a low grip strength. The linear relation in the scatter diagram (figure) also implies an increased risk as the grip strength decreases. Half the patients with a low grip strength did not develop complications, but the false-positive rate was about $50 \%$ for all the variables measured. Because grip strength was more sensitive and was low in $87 \%$ of the patients who developed complications, however, it had a far lower false-negative rate than the other tests and thus is a better screening test.

Skeletal muscle is an important reserve of amino-acids that are available for mobilisation in times of stress or starvation. ${ }^{14}$ This metabolic role of muscle is emphasised by the observations that half of total body protein turnover is accounted for by muscle protein, muscle protein breakdown is doubled after surgery, ${ }^{15}$ and grip strength declines rapidly in the immediate postoperative period.

A logical step, therefore, is to attempt to measure the size of muscle protein reserve. We recommend the use of grip strength as a simple and reliable method of detecting preoperative protein depletion. The test may be performed rapidly in the outpatient department; and a value above $85 \%$ of normal implies that the patients do not have appreciable malnutrition while a value below this indicates that a more detailed assessment is required.

We thank nursing staff on the surgical unit, who helped with some of the measurements, and $\mathrm{Mr} M \mathrm{D}$ Machin for overseeing the statistical analysis.

\section{References}

${ }^{1}$ Bistrian BR, Blackburn GL, Hallowell E. Protein status of general surgical patients. $\mathcal{F} A M A 1974 ; 230: 858-60$. 
2 Anonymous. Parenteral nutrition before surgery. Br Med f 1979;ii:1529.

${ }^{3}$ Studley HO. Percentage weight loss. A basic indicator of surgical risk in patients with chronic peptic ulcer. $\mathcal{F} A M A$ 1936;106:458-60.

4 Grosse E, Holbrook IB, Thornton M. Assessment of the nutritional state of patients with an intestinal fistula. Br 7 Surg 1978;65:740-3.

${ }^{5}$ Kammerling RM, Foster KJ, Karran SJ. Protein depletion and recovery from surgical operation. Br $\mathcal{F}$ Surg 1978;65:365.

${ }^{6}$ Metropolitan Life Insurance Company. Desirable weights for adults. Documenta Geigy. 8th ed. where?:Geigy, 1962:624.

${ }^{7}$ Jeliffe DB. The assessment of the nutritional status of the community. WHO Monogr Ser 1966;53.

${ }^{8}$ Swinscow TDV. Statistics at square one. 4th ed. London: British Medical Association, 1978:49.

9 Anonymous. Malnutrition and cancer. $\mathrm{Br} M e d \mathcal{f} 1979$;i:912-3.

10 Williams RHP, Heatley RV, Lewis M, Hughes LE. A randomised, con- trolled trial of pre-operative intravenous nutrition in patients with cancer of stomach. Brf Surg 1976;63:667.

11 Whitehead R, Coward W, Lunn PG. Serum-albumin concentration and the onset of kwashiorkor. Lancet $1973 ; \mathrm{i}: 63-6$.

12 Inglebleek Y, Van Den Schreik H, De Nayer P, De Visscher M. Albumin, transferrin and thryroxine binding pre-albumin/retinol-binding protein complex in the assessment of malnutrition. Clin Chim Acta 1975;63:61-7.

13 Buzby GP, Mullen JL, Matthews DC, et al. Prognostic Nutritional Index in gastro-intestinal surgery. Am $\mathcal{F}$ Surg 1980;139:160-7.

14 Daniel PM, Pratt OE, S'Argo E. Metabolic homeostatic role of muscle and its function as a store of protein. Lancet 1977;ii:446-8.

${ }^{15}$ Foster KJ, Alberti KGMM, Binder C, et al. Lipid metabolism and nitrogen balance after abdominal surgery. Br $\mathcal{F}$ Surg 1979;66:242-5.

(Accepted 27 August 1980)

\title{
Induction of labour with a sustained-release prostaglandin $\mathbf{E}_{2}$ vaginal pessary
}

\author{
M P EMBREY, N B GRAHAM, M E MCNEILL
}

\section{Summary and conclusions}

A new polymer vaginal pessary providing sustained constant release of prostaglandin $E_{2}$ was administered to 66 patients before planned induction of labour. Effective ripening of the unfavourable cervix was achieved in each of 18 primigravidas, in eight of whom labour was initiated without further treatment. When the cervix was moderately favourable the need for orthodox induction of labour was obviated in 16 out of 23 primigravidas and 21 out of 23 multigravidas.

This method of sustained release of prostaglandin $E_{2}$ is simple and convenient and readily acceptable to the patient; it is an important step in the development of non-invasive methods of inducing labour.

\section{Introduction}

Several recent studies have shown that the unfavourable prognosis for induction of labour signalled by an unripe cervix may be much improved by vaginal administration of prostaglandin $\mathrm{E}_{2}$ in simple gels and pessaries and that labour is often promoted without the need for formal induction. ${ }^{1-4}$ This method is increasingly favoured and would be still more widely used if a commercial product was available, but hitherto a prostaglandin $\mathrm{E}_{2}$ preparation with adequate long-term stability has not been developed. Additionally, experience suggests that a sustained-release vaginal preparation would be advantageous.

Initial laboratory studies incorporating prostaglandins in a water-swellable, cross-linked polymer (hydrogel) indicated that such a system should exhibit stability and provide sustained release of prostaglandin over prolonged intervals. ${ }^{5}$ We report on our early clinical experience of using a prostaglandin $E_{2}$ polymer vaginal pessary in the induction of labour.

Nuffield Department of Obstetrics and Gynaecology, University of Oxford, John Radcliffe Hospital, Headington, Oxford

M P EMBREY, MD, FRCOG, honorary consultant

Department of Pure and Applied Chemistry, University of Strathclyde, Glasgow

N B GRAHAM, BSC, PHD, young professor of chemical technology $M$ E MCNEILL, BSC, research assistant

\section{In-vivo studies}

We treated 66 patients (41 primigravidas, 25 multigravidas) requiring induction of labour for medical or obstetric reasons at 38-42 weeks' gestation. During the study period the dose of prostaglandin $\mathrm{E}_{2}$ incorporated in the pessary varied, depending on the formulation of the polymer and its in-vitro release profile. In most cases we used a pessary that in vitro released about $75 \%$ of its content over 12 hours; the incorporated dose of prostaglandin $E_{2}$ was $10 \mathrm{mg}$ for primigravidas and $5 \mathrm{mg}$ for multigravidas. Some patients who presented early in the trial, when a formulation with a less satisfactory profile was used, received a larger dose (up to $20 \mathrm{mg}$ in primigravidas).

Usually overnight and about 12 hours before induction was planned, the pessary was inserted in the vaginal vault after cervical assessment with a modified Bishop score. ${ }^{6}$ The patient remained recumbent for 15 minutes after insertion, and maternal pulse, blood pressure, uterine activity, and fetal heart rate were observed regularly for four to five hours and for longer if labour became established. Internal tocographic records showed that treatment provoked a pattern of frequent contractions (at one- to three-minute intervals) of low amplitude (less than $40 \mathrm{~mm} \mathrm{Hg}$ ) and causing little discomfort, starting after one to two hours: the contractions persisted for four to six hours and then either waned or were augmented as labour became established. The next day, if labour was not established, formal induction was performed by amniotomy followed if necessary by intravenous oxytocin. The pessary was removed when labour was established or at the time of amniotomy. The labour was managed by the duty delivery-suite staff.

\section{Results}

The establishment of labour after treatment depended on parity and was related to the initial cervical score (table). Labour was initiated by prostaglandin treatment alone in eight out of 18 primi-

Influence of parity and cervical score (0-4, cervix unfavourable; $>5$ cervix favourable) on establishment and outcome of labour. Figures are numbers of patients

\begin{tabular}{|c|c|c|c|c|}
\hline & \multicolumn{2}{|c|}{ Primigravidas } & \multicolumn{2}{|c|}{ Multigravidas } \\
\hline & $\underset{\substack{\text { Cervix } \\
\text { unfavourable }}}{(n=18)}$ & $\begin{array}{c}\text { Cervix } \\
\text { favourable } \\
(n=23)\end{array}$ & $\underset{\substack{\text { Cervix } \\
(n=2)}}{\text { unfavourable }}$ & $\begin{array}{c}\text { Cervix } \\
\text { favourable } \\
(n=23)\end{array}$ \\
\hline $\begin{array}{l}\text { Labour established } \\
\text { Oxytocin given } \ldots \\
\text { Epidural analgesia given ... } \\
\text { Spontaneousvaginaldelivery } \\
\text { Caesarean section .. }\end{array}$ & $\begin{array}{r}8 \\
9 \\
11 \\
5 \\
1\end{array}$ & $\begin{array}{r}16 \\
6 \\
8 \\
15 \\
-\end{array}$ & $\begin{array}{l}\overline{2} \\
\frac{2}{1}\end{array}$ & $\begin{array}{r}21 \\
2 \\
1 \\
23 \\
-\end{array}$ \\
\hline
\end{tabular}

